\title{
Effects of crude aqueous medicinal plant extracts on growth and invasion of breast cancer cells
}

\author{
SEVERINE VAN SLAMBROUCK ${ }^{1 *}$, AMBER L. DANIELS ${ }^{1 *}$, CARLA J. HOOTEN ${ }^{1}$, STEVEN L. BROCK ${ }^{1,2}$, \\ AARON R. JENKINS ${ }^{1}$, MARCIA A. OGASAWARA ${ }^{1}$, JOANN M. BAKER ${ }^{1}$, GLEN ADKINS ${ }^{1}$, EERIK M. ELIAS ${ }^{1}$, \\ VINCENT J. AGUSTIN ${ }^{1}$, SARAH R. CONSTANTINE ${ }^{1}$, MICHAEL J. PULLIN ${ }^{2}$, SCOTT T. SHORS ${ }^{4}$, \\ ALEXANDER KORNIENKO ${ }^{3}$ and WIM F.A. STEELANT ${ }^{1}$
}

\begin{abstract}
Laboratories of ${ }^{1}$ Biochemical and Biomedical Research, ${ }^{2}$ Aqueous Environmental Chemistry, ${ }^{3}$ Synthetic Organic and Medicinal Chemistry, and ${ }^{4}$ Virology, Department of Chemistry and Biology, New Mexico Tech, Socorro, NM, USA
\end{abstract}

Received December 7, 2006; Accepted January 22, 2007

\begin{abstract}
Plants used in folklore medicine continue to be an important source of discovery and development of novel therapeutic agents. In the present study, we determined the effects of crude aqueous extracts of a panel of medicinal plants on the growth and invasion of cancer cells. Our results showed that extracts of L. tridentata (Creosote Bush) and $J$. communis L. (Juniper Berry) significantly decreased the growth of MCF-7/AZ breast cancer cells. The latter as well as A. californica (Yerba Mansa) inhibited invasion into the collagen type I gel layer. Furthermore, the phosphorylation levels of extracellular signal-regulated kinase 1 and 2 (ERK1/2) decreased when the cells were exposed to aqueous extracts of L. tridentata, J. communis $L$. and A. californica. This study provides original scientific data on the anticancer activity of selected aqueous medicinal plant extracts used in traditional medicine.
\end{abstract}

\section{Introduction}

Since ancient times, plants, herbs and spices have been important resources in traditional medicine (1). The use of plants in the treatment of a variety of diseases, including cancer, has played a significant role in nearly every culture on earth and is the basis of modern medicine (2). Natural

Correspondence to: Professor Wim F.A. Steelant, Department of Chemistry, Laboratory of Biochemical and Biomedical Research, New Mexico Tech, 801 Leroy Place, Socorro, NM 87801, USA

E-mail: steelant@nmt.edu

${ }^{*}$ Contributed equally

Abbreviatons: ERK1/2, extracellular signal-regulated kinase 1 and 2; NDGA, nordihydroguaiaretic acid; OD, optical density; SRB, sulforhodamine B

Key words: medicinal plants, cancer cell growth, cancer cell invasion products are considered powerful sources of novel drug discovery and development. Their dominant role in anticancer chemotherapeutics is evident with approximately $74 \%$ being either natural products or natural product-derived $(3,4)$.

Cancer is a major health problem in the United States and other developed countries. Breast cancer, the most commonly diagnosed cancer among women, is the leading cause of death, resulting from the metastatic spread of primary tumors (5). Therefore, there is an ongoing need for both the improvement of current therapeutic strategies and the search for novel agents.

In a previous study, we investigated the effects of two medicinal plants, L. porteri (Osha) and A. californica (Yerba Mansa), used by Native American tribes, on the growth of human breast cancer cells. We reported that both the aqueous and ethanol extracts of A. californica, exert an extracellular signal-regulated kinase (ERK)-mediated growth inhibitory effect on MCF-7/AZ cells, whereas L. porteri showed no such activity (6). In the present study, we explored their effects on the invasiveness of human breast cancer cells and studied other plants habitually used in traditional medicine, including L. tridentata (Creosote Bush), J. communis L. (Juniper Berry), R. idaeus L. (Red Raspberry leaves), $C$. annuum L. (Green Chile) and T. vulgaris (Thyme). We examined the effects of each extract on the invasion and proliferation of human breast cancer cells in vitro and subsequently investigated changes in the activity level of ERK1/2.

The aim of this study was to evaluate the anticancer activity of crude aqueous extracts of medicinal plants used in traditional medicine in order to further identify active components or potential lead compounds.

\section{Materials and methods}

Plant materials and preparation of extracts. L. porteri, A. californica, L. tridentata, J. communis L., R. idaeus L., $C$. annuum $L$. and $T$. vulgaris were obtained from local herb stores or collected in New Mexico, USA. Cold aqueous extracts of each plant were prepared as follows: Seventy-five grams of the dried plants were soaked in water for $24 \mathrm{~h}$ at room temperature. The mixtures were then filtered to remove particulate matter and lyophilized. Table I shows the obtained 
Table I. The percentage (\%) yield obtained after the cold aqueous extraction of $75 \mathrm{~g}$ dried plant material.

\begin{tabular}{lcr}
\hline & $\begin{array}{c}\text { Dry material } \\
\text { after extraction (g) }\end{array}$ & $\begin{array}{c}\% \\
\text { yield }\end{array}$ \\
\hline C. annuum L. (Green Chile) & 18 & 23 \\
L. tridentata (Creosote Bush) & 7 & 9 \\
T. vulgaris (Thyme) & 18 & 17 \\
R. idaeus L. (Red Raspberry leaves) & 20 & 27 \\
L. porteri (Osha) & 14 & 18 \\
A. californica (Yerba Mansa) & 5 & 7 \\
J. communis L. (Juniper Berry) & 6 & 8 \\
\hline
\end{tabular}

yields of the different plant extracts. The resulting powders were stored in a desiccator at $4^{\circ} \mathrm{C}$.

Cell culture. MCF-7/AZ is a variant of the human mammary carcinoma cell family MCF-7 (7). The cells were maintained on a tissue culture plastic substrate (Nunc) in a mixture of Dulbecco's modified Eagle's medium (DMEM) and HAMF12 (50/50) (Invitrogen, Carlsbad, CA, USA) supplemented with $250 \mathrm{IU} / \mathrm{ml}$ penicillin, $100 \mu \mathrm{g} / \mathrm{ml}$ streptomycin (Invitrogen) and $10 \%$ fetal bovine serum (FBS) (Invitrogen), at $37^{\circ} \mathrm{C}$ in a humidified atmosphere containing $10 \% \mathrm{CO}_{2}$.

Assay for cell viability. Cell viability was tested in accordance with Romijn et al (8). Briefly, mitochondrial dehydrogenase activities were measured by an MTT-reagent (Sigma, St. Louis, MO, USA). Cells were seeded in microtiter plates at an initial density of $1.5 \times 10^{4}$ cells in $200 \mu 1$ culture medium and treated with increasing concentrations of each plant extract. In each experiment, eight wells were used to determine the mean optical dentisty (OD) referring to the cell viability.

Assay for cell growth. Cells were seeded in microtiter plates at an initial density of $1.5 \times 10^{4}$ cells in $200 \mu$ l culture medium and treated with increasing concentrations of each plant extract. After an incubation period of 4 days the amount of cell protein in each well was estimated with the sulforhodamine B (SRB) assay (9) or the cells were counted with a hemacytometer (Hausser Scientific, Horsham, PA, USA).

Collagen type I invasion assay. This was performed as described previously (10). Briefly, six-well plates were filled with $1.25 \mathrm{ml}$ neutralized type I collagen $(0.09 \%)$ (Upstate Biotechnology, Lake Placid, NY, USA) and incubated for $1 \mathrm{~h}$ at $37^{\circ} \mathrm{C}$ to allow gelification. Non-invasive MCF-7/AZ cells were pretreated with ET-18-OMe for $24 \mathrm{~h}$ in order to become invasive into collagen type I (11) and served as the control for invasiveness as compared to untreated MCF-7/AZ cells. Single cell suspensions were prepared with trypsin/ EDTA, mixed with the different extracts, seeded on top of collagen type I gel and cultured at $37^{\circ} \mathrm{C}$ for $24 \mathrm{~h}$. The number of cells penetrating into the gel or remaining at the surface was counted in 12 fields of $0.157 \mathrm{~mm}^{2}$, using an inverted microscope controlled by a computer program. The invasion
Table II. $\mathrm{OD}_{80}$ values for each aqueous plant extract as determined by MTT assay after 24-h exposure.

\begin{tabular}{lc}
\hline & $\begin{array}{c}\text { MCF-7/AZ OD } \\
\text { values }(\mu \mathrm{g} / \mathrm{ml}\end{array}$ \\
\hline C. annuum L. (Green Chile) & $>80$ \\
L. tridentata (Creosote Bush) & $>180$ \\
T. vulgaris (Thyme) & 160 \\
R. idaeus L. (Red Raspberry leaves) & 80 \\
L. porteri (Osha) & $>180$ \\
A. californica (Yerba Mansa) & 60 \\
J. communis L. (Juniper Berry) & 50 \\
\hline
\end{tabular}

index expresses the percentage of invading cells over the total number of cells.

Western blotting. Cell lysates were made from $70 \%$ confluent cultures. The cells were treated for specified amounts of time with aqueous extracts of $J$. communis $L$. and $L$. tridentata. After incubation, the cells were washed three times with PBS and lysed in $0.5 \mathrm{ml}$ lysis buffer containing $1 \%$ Triton $\mathrm{X}-100$, $1 \% \mathrm{NP}-40$ and the following protease inhibitors: Aprotinin $(10 \mu \mathrm{g} / \mathrm{ml})$, leupeptin $(10 \mu \mathrm{g} / \mathrm{ml})$, PMSF $(1.72 \mathrm{mM}), \mathrm{NaF}$ $(100 \mathrm{mM}), \mathrm{NaVO}_{3}(500 \mu \mathrm{M})$ and $\mathrm{Na}_{4} \mathrm{P}_{2} \mathrm{O}_{7}(500 \mu \mathrm{g} / \mathrm{ml})$. Protein concentration was determined using the Pierce BCA protein assay kit (Pierce, Rockford, IL, USA). Aliquots of the lysates containing the same quantity of proteins were boiled for $5 \mathrm{~min}$ in sodium dodecyl sulfate polyacrylamide gel electrophoresis (SDS-PAGE) sample buffer containing 5\% ß-mercaptoethanol, electrophoresed on 7.5\% SDS-PAGE and transferred to PVDF membranes. After the transfer, the membranes were incubated with primary anti-phospho-ERK1/2 (1:1000) (Cell Signaling Technologies, Beverly, MA, USA), followed by incubation with a secondary biotinylated antibody (1:1000) and development by the enhanced chemiluminescence (ECL) detection kit (Vector Labs, Burlingame, CA, USA). The membranes were imaged and analyzed on the BioChemi System and analysis software (UVP, Upland, CA, USA).

Statistics. All treatments were matched and carried out at least 3 times. The Student's t-test $(95 \%)$ was used for the statistical evaluation of the SRB, ERK1/2 phosphorylation and collagen type I invasion assay. The levels of phospho-ERK1/2 were quantified using Scion Image statistical software (Scion Corporation, Frederick, MD, USA).

\section{Results}

Effects of plant extracts on cell viability. The cytotoxic activity of each aqueous plant extract was determined on MCF-7/AZ breast cancer cells after $24-\mathrm{h}$ exposure. A concentrationdependent decrease in cell viability was observed for the extracts of $R$. idaeus $L$. and $J$. communis $L$., whereas no significant changes were detected for $C$. annuum L., T. vulgaris and L. tridentata (data not shown). The cytotoxic effects of L. porteri and A. californica were previously determined (6). 
A

Extract
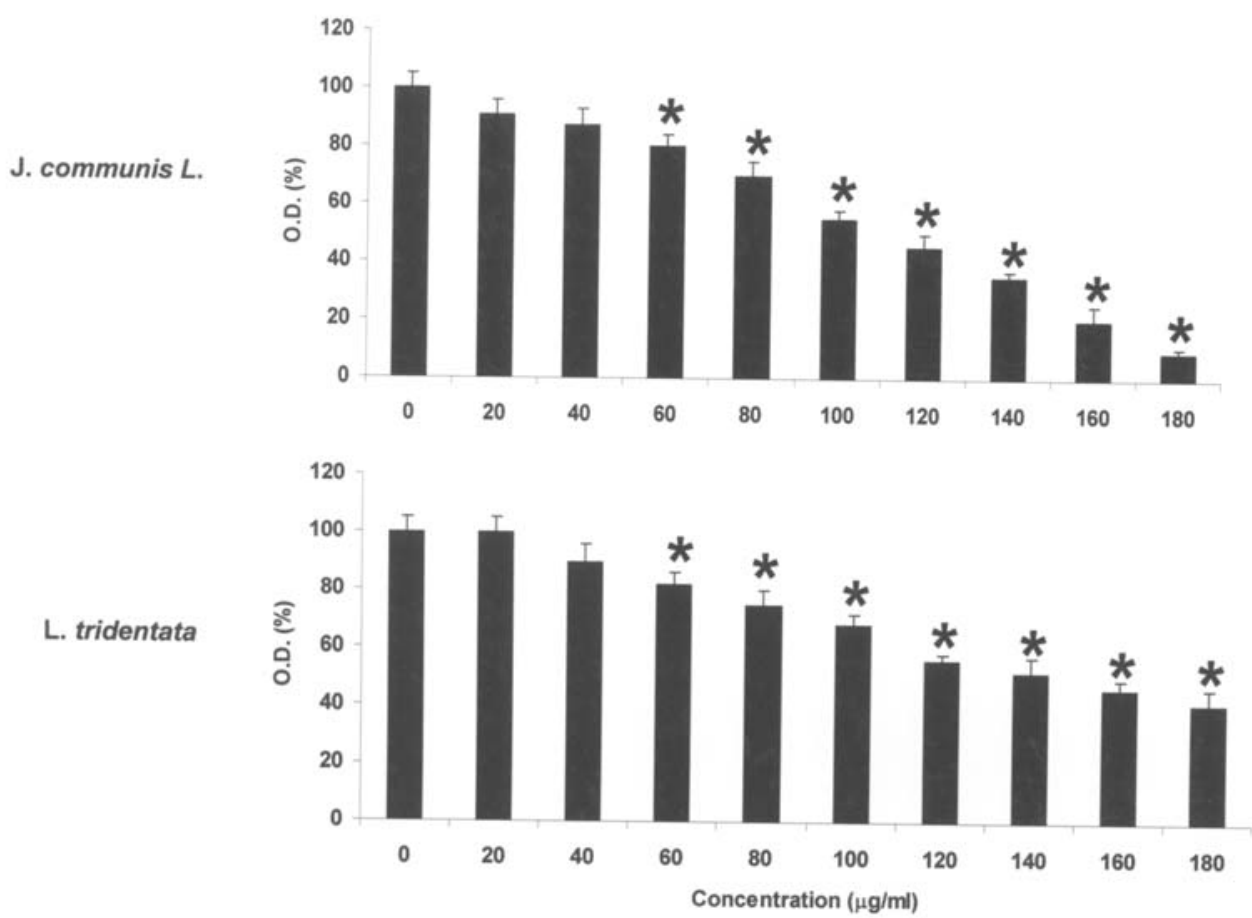

B

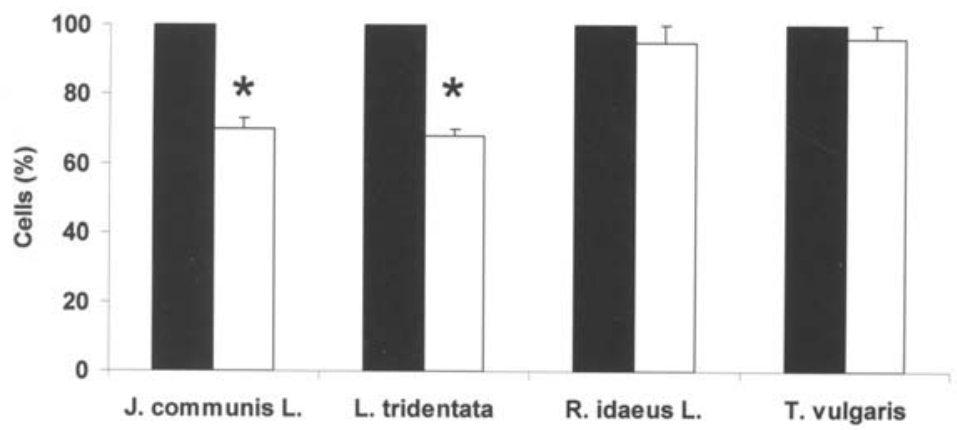

Figure 1. Growth-inhibitory effects of aqueous extracts of J. communis L. (Juniper Berry) and L. tridentata (Creosote Bush). (A) MCF-7/AZ breast cancer cells were exposed to increasing concentrations of J. communis L. and L. tridentata for 4 days, and the amount of cellular protein was measured with the SRB assay and expressed as OD. The bars and flags indicate the mean values and standard deviations. The asterisks indicate statistical differences from the controls. (B) MCF-7/AZ cells were exposed to J. communis L., L. tridentata, R. idaeus L. (Red Raspberry leaves) and T. vulgaris (Thyme) extracts at 50 , 180,80 and $160 \mu \mathrm{g} / \mathrm{ml}$, respectively, for 4 days, and the number of cells was determined by counting and expressed as a percentage of the control cells. The bars and flags indicate the mean values and standard deviations. The asterisks indicate statistical differences from the controls.

For further experiments, the $\mathrm{OD}_{80}$ values were used, leaving $\sim 80 \%$ of the cells viable (Table II).

Effects of plant extracts on cell growth.

$S R B$ assay. Aqueous extracts of $J$. communis $L$. and $L$. tridentata markedly inhibited the growth of MCF-7/AZ cells in a concentration-dependent manner (Fig. 1A). All the other extracts showed no effect on the growth of MCF-7/AZ cells (data not shown).

Cell counting. MCF-7/AZ cells exposed to extracts of $J$. communis L. and L. tridentata, at 50 and $180 \mu \mathrm{g} / \mathrm{ml}(80 \%$ viability), respectively, showed a $30 \%$ decrease in cell proliferation as compared to the control cells (Fig. 1B), whereas no anti-proliferative effect was observed for the other extracts, as shown for $R$. idaeus $L$. and T. vulgaris. These findings are consistent with the results obtained from the SRB assay (Fig. 1A)

Effects of plant extracts on invasion into collagen type I gel layer. MCF-7/AZ cells are non-invasive into the collagen type I gel layer. ET-18-OMe treatment, however, induces invasion into collagen type I (11). J. communis $L$. and $A$. californica significantly reduced the induced invasion of MCF-7/AZ cells into collagen type I. No such effect was observed for the other plant extracts (Fig. 2).

Time-dependent effects of plant extracts on phosphorylation of ERK1/2. Exposure of MCF-7/AZ cells to aqueous extracts of $J$. communis $L$. and $L$. tridentata significantly decreased the phosphorylation levels of ERK as compared to the controls (Fig. 3). No changes in the phosphorylation levels were 


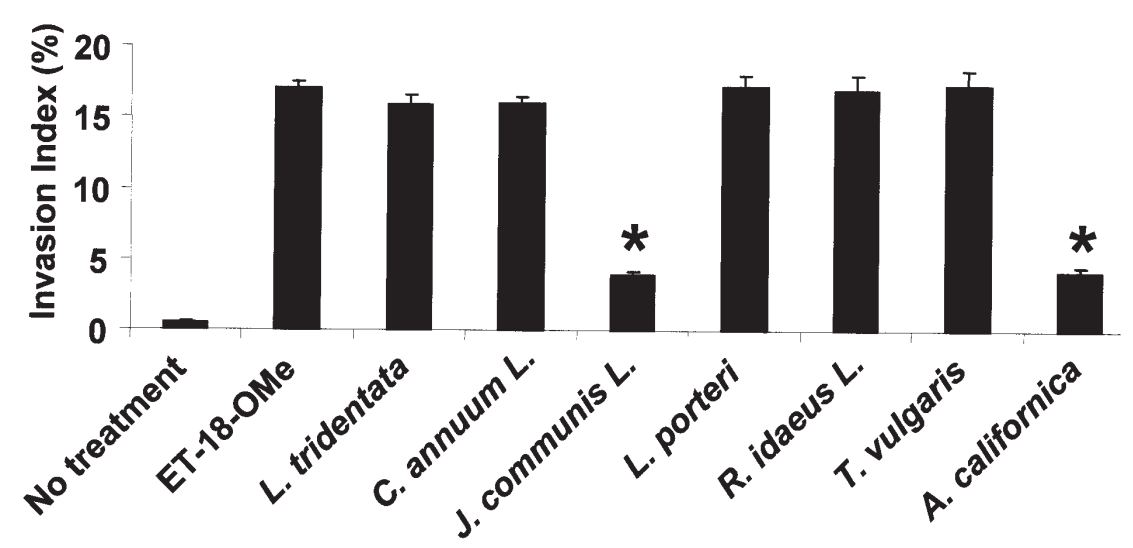

Figure 2. Anti-invasive effects of aqueous extracts of J. communis L. (Juniper Berry) and A. californica. (Yerba Mansa) ET-18-OMe-induced invasive MCF7/AZ cell suspensions were seeded on top of collagen type I gel, exposed to each plant extract in concentrations as determined by the MTT assay (Table II) and cultured at $37^{\circ} \mathrm{C}$ for $24 \mathrm{~h}$. The invasion index expresses the percentage of invading cells into collagen type I over the total number of cells. The controls included untreated MCF-7/AZ and ET-18-OMe-treated (invasive) MCF-7/AZ cells. The bars and flags indicate the mean values and standard deviations. The asterisks indicate statistical differences from the ET-18-OMe-treated MCF-7/AZ cells.

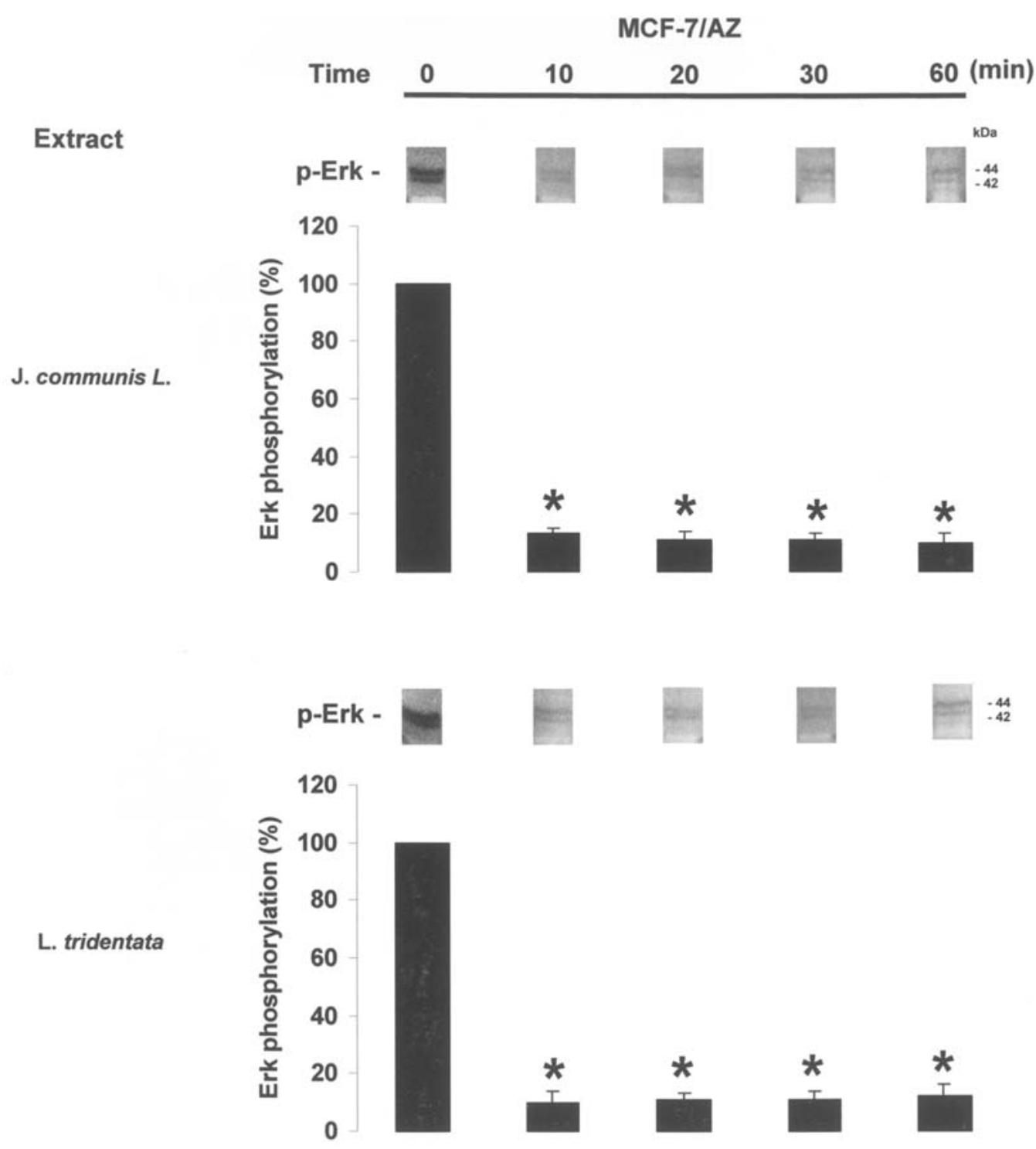

Figure 3. Effects of aqueous extracts of J. communis L. (Juniper Berry) and L. tridentata (Creosote Bush) on ERK1/2 phosphorylation. MCF-7/AZ cells were exposed to $50 \mu \mathrm{g} / \mathrm{ml}$ and $180 \mu \mathrm{g} / \mathrm{ml}$, respectively of $J$. communis $L$. and L. tridentata extracts for specified amounts of time. Whole cell lysates, containing $30 \mu \mathrm{g}$ protein, were analyzed by 7.5\% SDS-PAGE and immunoblotted with antibody against activated ERK (p-ERK, Thr202/Tyr204). The membranes were stripped at $50^{\circ} \mathrm{C}$ for $30 \mathrm{~min}$ in stripping buffer (100 $\mathrm{mM} \mathrm{B-mercaptoethanol,} 2 \% \mathrm{SDS}, 62.5 \mathrm{mM}$ Tris-HCl pH 6.8) and reblotted with antiERK (data not shown). Scion image densitometry analysis of bands of activated ERK (p-ERK, Thr202/Tyr204), is expressed as the percentage of unexposed cells. The bars and flags indicate the mean values and standard deviations. The asterisks indicate statistical differences from the controls. 
observed when the cells were exposed to the other aqueous extracts (data not shown). The total levels of ERK were unaltered upon exposure (data not shown).

\section{Discussion}

Historically, plants, herbs and spices were a folkloric source of medicinal agents, and as modern medicine expanded, many useful drugs were developed from lead compounds discovered from medicinal plants. This approach has provided leads against various pharmacological targets, including cancer, $\mathrm{HIV}$, malaria and pain, and remains an important route to new pharmaceuticals $(1-4,12)$.

In this study, we analyzed the effects of several medicinal plant extracts on the proliferation and invasion of MCF-7/AZ breast cancer cells. Aqueous extracts prepared from each medicinal plant showed no significant cytotoxic activity at concentrations lower than $50 \mu \mathrm{g} / \mathrm{ml}$. MCF-7/AZ cells exposed to aqueous extracts from $J$. communis $L$. and $L$. tridentata potently inhibited the growth of MCF-7/AZ cells compared to unexposed cells as determined by SRB studies. The growth-inhibitory effect of $L$. tridentata has previously been reported (13) and is attributed to its major phenolic constituent, nordihydroguaiaretic acid (NDGA) (14). Certain anticancer properties of NDGA are related to the inhibition of receptor tyrosine kinases (RTKs), the insulin-like growth factor receptor (IGF-1R) and the c-erbB2/HER2/neu (HER2/neu) receptor (15). This correlates with our findings, namely with the decreased phosphorylation levels of ERK, since ERK is a downstream effector molecule of both receptors $(16,17)$. Additionally, this compound is a general inhibitor of lipoxygenases (18), the latter playing a crucial role in cancer cell survival and apoptosis, through the release of cytochrome c and the activation of specific caspases (19). Since extracts of $J$. communis $L$. inhibited the growth of cancer cells, we speculated that changes in ERK activity could be responsible for the growth inhibitory effects, given the fact that many plant-derived components modulate ERK activities in order to elicit their anti-neoplastic actions (20-22). A recent study also reveals that extracts of $J$. communis $L$. also inhibit $12-$ lipoxygenases (23). The possibility that $J$. communis $L$. and L. tridentata influence cell survival through the inhibition of lipoxygenases and the subsequent activation of caspases $(19,24)$ was ruled out since no differences in caspase activities could be detected for either extract (data not shown). Furthermore, we could not detect any anticancer activities of $T$. vulgaris and $R$. idaeus $L$. Much controversy exists on the anticancer activity of capsaicin, the principical ingredient of Chili peppers (25). We, however, could not observe an inhibiting or stimulating effect of the aqueous extract of $C$. annuит $L$. in our experimental model.

Invasive capacity is the single most important characteristic that distinguishes benign from malignant lesions. It is now increasingly accepted that the invasion process offers a rich source of novel targets for therapy and inhibitors can control metastasis. One key event in this complex process is the penetration into the surrounding extracellular matrix (ECM), mainly consisting of collagens, and this was mimicked by using a collagen type I invasion assay (26). The effects of each aqueous extract were tested on ET-18-OMe-induced invasive MCF-7/AZ cells (11). Our findings revealed that $J$. communis $L$. and A. californica efficiently inhibited invasion, which could also be ascribed to the inhibition of the ERK activity (6). There is increasing evidence that ERK is an important mediator in the acquisition of a malignant phenotype, due to its role in multiple branching signaling pathways. Consequently, the specific blockade of ERK results not only in an anti-proliferative effect but also in an anti-invasive effect (27). Although aqueous extracts of $L$ tridentata decreased ERK phosphorylation levels and earlier study has indicated that NDGA inhibits the expression of the intracellular adhesion molecule-1 (ICAM-1) on tumor cells (28) and is thus valuable for the treatment of metastasis, we did not find any inhibitory effect of $L$ tridentata on invasion. An explanation could be, that despite the presence of NDGA in aqueous extracts of $L$. tridentata, the activity of the extract can not be attributed to NDGA itself but rather to other components or influences of NDGA on the activity of other compounds present. A similar assumption was made for the extracts of $L$. divaricata and NDGA (29).

To the best of our knowledge, this is the first publication demonstrating that $J$. communis $L$. inhibits the growth of cancer cells, and that both J. communis L. and A. californica exert an anti-invasive effect. In addition, these results indicate that aqueous extracts of $J$. communis L. and A. californica comprise active components or potential leads that could be useful in cancer treatment. Studies along this line are currently being carried out in our laboratories.

\section{Acknowledgements}

This study is supported by the US National Institutes of Health (RR-16480) under the BRIN/INBRE program of the National Center for Research Resources and the New Mexico Tech startup funds.

\section{References}

1. Akelere O: Nature's medicinal bounty: don't throw it away. World Health Forum 14: 390-395, 1993.

2. Jones WP, Chin YW and Kinghorn AD: The role of pharmacognosy in modern medicine and pharmacy. Curr Drug Targets 7: 247-264, 2006.

3. Cragg GM and Newman DJ: Plants as a source of anti-cancer agents. J Ethnopharmacol 100: 72-79, 2005.

4. Tan G, Gyllenhaal C and Soejarto DD: Biodiversity as a source of anticancer drugs. Curr Drug Targets 7: 265-277, 2006.

5. Jemal A, Siegel R, Ward E, Murray T, Xu J, Smigal C and Thun MJ: Cancer Statistics. CA Cancer J Clin 56: 106-130, 2006.

6. Daniels AL, Van slambrouck S, Lee RK, Arguello TS, Browning J, Pullin MJ, Kornienko A and Steelant WFA: Effects of extracts from two Native American plants on proliferation of human breast and colon cancer cell lines in vitro. Oncol Rep 15: 1327-1331, 2006.

7. Bracke ME, Van Larebeke NA, Vyncke BM and Mareel MM: Retinoic acid modulates both invasion and plasma membrane ruffling of MCF7 human mammary carcinoma cells in vitro. $\mathrm{Br}$ J Cancer 63: 867-872, 1991.

8. Romijn JC, Verkoelen CF and Schroeder FH: Application of the MTT-assay to human prostate cancer cell lines in vitro: establishment of test conditions and assessment of hormonestimulated growth and drug-induced cytostatic and cytotoxic effects. Prostate 12: 99-110, 1988.

9. Skehan P, Stroeng R, Scudiero D, Monks A, McMahon J, Vistica D, Warren JT, Bokesch H, Kenney S and Boyd MR: New colorimetric cytotoxicity assay for anticancer drug screening. J Natl Cancer Inst 82: 1107-1112, 1990. 
10. Bracke ME, Boterberg T, Bruyneel EA and Mareel MM: Collagen Invasion Assay. In: Metastasis Methods and Protocols. Brooks S and Schumzcher U (eds). Hannover Press, Totowa, NJ, USA, 1999.

11. Steelant WF, Goeman JL, Philippe J, Oomen LC, Hilkens J, Krzewinski-Recchi M-A, Huet G, Van der Eycken J, Delannoy P, Bruyneel EA and Mareel MM: Alkyl-lysophospholipid 1-Ooctadecyl-2-O-methyl- glycerophosphocholine induces invasion through episialin-mediated neutralization of E-cadherin in human mammary MCF-7 cells in vitro. Int J Cancer 92: 527536,2001

12. Balunas MJ and Kinghorn AD: Drug discovery from medicinal plants. Life Sci 78: 431-441, 2005.

13. Lambert JD, Sang S, Sougherty A, Caldwell CG, Meyers RO, Dorr RT and Timmermann BN: Cytotoxic lignans from Larrea tridentata. Phytochemistry 66: 811-815, 2005.

14. Moody TW, Leyton J, Martinez A, Hong S, Malkinson A and Mulshine JL: Lipoxygenase inhibitors prevent lung carcinogenesis and inhibit non-small lung cancer growth. Exp Lung Res 24: 617-628, 1998.

15. Youngren JF, Gable K, Penaranda C, Maddux BA, Zavodovskaya M, Lobo M, Campbell M, Kerner J and Goldfine ID: Nordihydroguaiaretic acid (NDGA) inhibits IGF-1 and cerbB2/HER2/ neu receptors and suppresses growth in breast cancer cells. Breast Cancer Res Treat 94: 37-46, 2005.

16. Kurihara S, Hakuno F and Takashashi S: Insulin-like growth factor-I-dependent signal transduction pathways leading to the induction of cell growth and differentiation of human neuroblastoma cell line SH-SY5Y: the roles of MAP kinase pathway and PI 3-kinase pathway. Endocr J 47: 738-751, 2000.

17. Spencer KS, Graus-Porta D, Leng J, Hynes NE and Klemke RL: ErbB2 is necessary for induction of carcinoma cell invasion by ErbB2 family of receptor tyrosine kinases. J Cell Biol 148: 385-397, 2000.

18. Ding XZ, Kuszynski CA, El-Metwally TH and Adrian TE: Lipoxygenase inhibition induced apoptosis, morphological changes, and carbonic anhydrase expression in human pancreatic cancer cells. Biochem Biophys Res Commun 266: 329-399, 1999.
19. Tong WG, Ding X Z and Adrian TE: The mechanism of lipoxygenase inhibitor-induced apoptosis in human breast cancer cells. Biochem Biophys Res Commun 296: 942-948, 2002.

20. Agarwal C, Sharma Y and Agarwal R: Anticarcinogenic effect of a polyphenolic fraction isolated from grape seeds in human prostate carcinoma DU145 cells: modulation of mitogenic signaling and cell-cycle regulators and induction of G1 arrest and apoptosis. Mol Carcinog 28: 129-138, 2000.

21. Izevbigie EB, Bryant JL and Walker A: A novel natural inhibitor of extracellular signal-regulated kinases and human breast cancer cell growth. Exp Biol Med 229: 163-169, 2004.

22. Zhang CL, Wu LJ, Tashiro S, Onodera S and Ikejima T: Oridonin induces caspase-independent but mitochondria-and MAPK-dependent cell death in the murine fibrosarcoma cell line L929. Biol Pharm Bull 27: 1527-1531, 2004.

23. Schneider I, Gibbons S and Bucar F: Inhibitory activity of Juniperus communis on 12(S)-HETE production in human platelets. Planta Med 70: 471-474, 2004

24. Wong BC, Wang WP, Cho CH, Fan XM, Lin MC, Kung HF and Lam SK: 12-Lipoxygenase inhibition induced apoptosis in human gastric cancer cells. Carcinogenesis 22: 1349-1354, 2001.

25. Surh Y: More than spice: Capsaicin in hot chili peppers makes tumor cells commit suicide. J Natl Cancer Inst 94: 1263-1265, 2002.

26. Mareel M and Leroy A: Clinical, cellular and molecular aspects of cancer invasion. Physiol Rev 83: 337-376, 2003.

27. Kohno $\mathrm{M}$ and Pouyssegur J: Targeting the ERK signaling pathway in cancer therapy. Ann Med 38: 200-211, 2006.

28. Wang Y, Zhou B, Li J, Cao YB, Chen XS, Cheng MH and Yin M: Inhibitors of 5-lipoxygenase inhibit expression of intracellular adhesion molecule-1 in human melanoma cells. Chung Kuo Yao Li Hsueh Pao 25: 672-677, 2004.

29. Anesini C, Ferraro G, Lopez P and Borda E: Different intracellular signals coupled to the antiproliferative action of aqueous crude extract from Larrea divaricata Cav. and nordihydroguaiaretic acid on lymphoma cell line. Phytomedicine 8: $1-7,2001$. 